\title{
Therapy-Related Neoplasm
}

National Cancer Institute

\section{Source}

National Cancer Institute. Therapy-Related Neoplasm. NCI Thesaurus. Code C3487.

The development of a neoplasm in response to medical or surgical treatment, induced by the treatment itself. 